OPEN ACCESS

Edited by:

Silke Hertel,

Heidelberg University, Germany

Reviewed by:

Scott Miller,

University of Florida, United States

Caroline Cohrssen,

The University of Hong Kong,

Hong Kong

${ }^{*}$ Correspondence:

Cristiana Levinthal

cristiana.levinthal@helsinki.fi

Specialty section

This article was submitted to

Educational Psychology,

a section of the journal

Frontiers in Education

Received: 30 November 2020

Accepted: 15 March 2021

Published: 09 April 2021

Citation:

Levinthal C, Kuusisto E and Tirri K (2021) How Finnish and Portuguese

Parents' Implicit Beliefs About

Learning Actualize at Home.

Front. Educ. 6:635203.

doi: $10.3389 /$ feduc.2021.635203

\section{How Finnish and Portuguese Parents' Implicit Beliefs About Learning Actualize at Home}

\author{
Cristiana Levinthal ${ }^{1 *}$, Elina Kuusisto ${ }^{1}$ and Kirsi Tirri ${ }^{2}$ \\ ${ }^{1}$ Faculty of Educational Sciences, University of Helsinki, Helsinki, Finland, ${ }^{2}$ Faculty of Education and Culture, Tampere \\ University, Tampere, Finland
}

The purpose of this qualitative study was to explore parental engagement in the home learning environment, and parents' implicit beliefs about learning underlying such engagement. Nineteen parents of school children between 7 and 12 years old were interviewed in two different cultural contexts, Finland $(N=10)$ and Portugal $(N=9)$. The interviews were subjected to inductive and deductive content analysis. Forms of parental engagement at home were similar in both countries, divided between two main categories: engagement with their child's holistic development and engagement with the child's schooling process. Parental narratives about engagement were, for the most part, embedded in a growth mindset (or an incremental meaning system). The most common actualizations of engagement included considering the child's learning contexts and emotions; encouraging effort, persistence and practice; approaching difficulties as a natural part of learning and suggesting strategies for overcoming them. Parental practices of engagement were combined with the actualization of their implicit beliefs to create parental engagement-mindset profiles. Twelve parents were classified as having a growth mindset to support the child's holistic development profile, and the other seven were distributed amongst the three remaining profiles. The study contributes to the growing interest on the association between parental engagement and their learning-related implicit beliefs, giving clear first-person illustrations of how both occur and interact in the home learning environment. Implications for practice are discussed.

Keywords: parental mindset, parental engagement, learning in the home, holistic development, Finland, Portugal

\section{INTRODUCTION}

Research conducted over the past 40 years has highlighted the centrality of parental involvement in children's schooling and achievement (Grolnick and Slowiaczek, 1994; Epstein, 2011). However, the latest tendencies in global educational goals encourage a shift of the parental role in their children's learning and call for a different approach (OECD, 2012; Goodall, 2017). Parents have traditionally been seen as allies who support the schools' goals and who are sporadically involved in their children's schools or schooling (Epstein, 2011). As the realization dawns that versatile citizens are as essential to society as well-trained professionals, there is an increasing emphasis on truly engaging parents with their children's learning. Parents are, therefore, perceived as valuable partners (Goodall and Montgomery, 2014) in a learning process that includes the acquisition of transferrable home-school-work life competences such as managing daily life, active participation, 
and interaction (FNBE - Finnish National Board of Education, 2016; DGE - Direção-Geral de Ensino, 2017; OECD, 2018, p. 4).

Carol Dweck's (2000) self-theories framework, or mindset theory, has been successful in enhancing understanding of people's approaches to learning-related situations in an array of contexts, such as work life, sports or the classroom. According to the author (Dweck, 2000, 2006); the mindset theory postulates that a person's mindset refers to implicit beliefs about their basic abilities. Thus, an individual with a growth mindset (or incremental implicit theory) believes his or her abilities can be developed through effort and will persist in the face of challenges in order to learn from them. On the other hand, an individual with a fixed mindset (or entity implicit theory) believes abilities cannot be changed and will be less motivated to learn from difficult situations. Mindset is considered a major element to be taken into account in the fight against inequitable education and the stereotyping of disadvantaged students (Dweck, 2010). Therefore, it has lately been gaining ground in studies of parenting styles and parental engagement with learning in the home (e.g., Moorman and Pomerantz, 2010; Muenks et al., 2015; Schiffrin et al., 2019; Justice et al., 2020).

Most of these quantitative studies focus on how the parental mindset about the fixedness of their children's abilities is associated with their engagement in their children's learningrelated activities at home, and with parenting styles such as controlling versus autonomy-supportive. The findings are promising, indicating that the parental mindset may be associated with various patterns of parental style and engagement at home (Muenks et al., 2015), and that it could even serve as a predictor of specific forms of engagement (Justice et al., 2020). Such studies open new avenues for addressing old problems related to engaging all families and using the home environment of every pupil to support learning (Goodall, 2013). They also highlight the importance of studying different cultural settings to explore the variability of the parental mindset and engagement in their children's learning (Justice et al., 2020).

Existing research on the parental mindset is predominantly, if not entirely, questionnaire-based. Our aim is to broaden the methodological perspective by utilizing qualitative approaches, allowing phenomena to be studied in a way that presents their character on a deeper level (Larsson, 1998). This study, therefore, is intended to contribute to the debate on the parental engagement-mindset theme. Through parents' own narratives, we explore how they engage with their children's learning at home, and their mindsets regarding such engagement.

Finland and Portugal were selected for this study as both have recently been through major core curriculum reforms with a very similar aim. Finland and Portugal seek to adapt the goals of their curricula to a holistic perspective, aiming for students to develop not only competences in individual fields of knowledge, but also competences of the whole person (e.g., autonomy and teamwork) (FNBE - Finnish National Board of Education, 2016; DGE - Direção-Geral de Ensino, 2017). Nevertheless, Finland and Portugal implement their holistic educational goals from different starting points. Finland has undoubtedly been an example of well implemented educational reforms through decades (Tirri, 2014), serving as a model of good practices.
Finland is, therefore, a promising environment for fruitful lessons about parental engagement to emerge. Therefore, our results will inform research and practice on how the home learning environment may be considered to support children's learning more effectively, in Finland, Portugal and other countries undergoing similar reforms.

\section{Parental Engagement and the Home Learning Environment}

A considerable body of research indicates that parental involvement in learning enhances school achievement among their children (for a meta-analysis, see Wilder, 2014). As a result, there has been extensive interest about the parental role in education over the decades, as researchers have questioned how this could better serve the schooling process (Grolnick et al., 1997). More recently, there has been a shift from a school-centered to a learning-centered approach, attention being directed to interactions in the home and parenting styles, instead of mere parental participation in school or schooling (e.g., Goodall, 2013; Sikiö et al., 2017).

According to Goodall and Montgomery (2014), the parental role could better facilitate the learning process of children if viewed as a three-point continuum of engagement with learning. The continuum covers what parents do both at school and at home. In practical terms, a continuum of parental engagement with learning means that parent and child constantly navigate through a variety of interactions that support the child's learning: for instance, from attending presentations or meetings in the school (engagement with the school), supervising or helping with homework at home (engagement with the schooling) to chatting with the child about their friendships or after-school football practice around the dinner table (engagement with learning). This third point has been described as the ultimate form of enhancing the home learning environment and relationships, in which both teachers and parents focus on the child as a whole person, and not solely on schooling goals. It constitutes genuine parental interest and support in all learning-related aspects of the child's life, accompanied by a stronger feeling of parental ownership of actions toward their children's learning. The framework acknowledges traditional forms of involvement as part of the continuum and argues that the more effective parental role in learning is engagement with their children's holistic development. Here, school, schooling and outside-ofschool matters have equivalent importance and need for parental engagement in the life of a child (for a recent review on parental involvement and engagement, see Levinthal and Kuusisto, 2020).

This perspective builds on previous research attesting to the high relevance of the home learning environment. For example, longitudinal studies based on information from more than 3,000 3- to 7-year-old children and their educational contexts revealed that the home learning environment was the single strongest contextual factor affecting children's cognitive development. What parents did to support and encourage learning outside of the school context mattered more than their profession, income, or even educational level (Sylva et al., 2004). Children with higher scores on intellect and social behavior, for example, had parents 
who engaged in reading with them, taught them songs and nursery rhymes, taught and played with letters and numbers, and engaged in painting, drawing, and visiting the library together. According to the findings, these parents would also create regular opportunities for their children to play with friends at home. Another study involving parents of kindergarten children from white, black and Hispanic ethnic background (Chen et al., 2012) reported a similar set of literacy activities amongst all ethnic groups as forms of engagement in the home. However, little is known about such ludic and broad forms of parental engagement among school-age children.

Studies on parental engagement at home from primary education onward assign a central role to homework supervision. Given the stronger association of home-based - over schoolbased - parental involvement with children's outcomes (for a meta-analysis, see Hill and Tyson, 2009), homework support has been studied from different perspectives. Having conducted a meta-analysis of 52 quantitative studies on parental involvement, Jeynes (2007) concluded that, although supervising homework might be a commonsense strategy for getting involved in children's learning, it does not affect school attainment. A more recent meta-analysis aimed to analyze common findings from studies regarding the relationship between parental involvement and student academic achievement. The author (Wilder, 2014) highlighted that, from the ten different definitions of parental involvement among the nine studies analyzed, the ones that defined involvement as homework assistance revealed no positive relationship or a negative correlation between homework assistance and academic achievement. On the other hand, it is reported in a recent study based on interviews with eight parents (Braunschweig et al., 2019) that the non-existence of homework could be perceived by parents as a loss of control over their children's learning, requiring the adaptation of school-home communication. According to Goodall (2013), more than helping with homework, what influences children's achievement is when parents link what is being learned at school with other aspects of their children's lives, and when they provide structure at home. Structure, in turn, constitutes a key dimension of parenting that contributes to optimal involvement, together with parental support of children's autonomy, positive affect, and support of process-focused learning (Pomerantz et al., 2012).

The debate on homework heralded a focus on parenting styles of involvement (e.g., Cooper et al., 2000). It is reported in a quantitative study among Portuguese elementary- and middleschool children (Mata et al., 2018) that those who perceived their parents as being more interested and learning-engaged tended to see interactions related to homework and conversations about school as more positive. Accordingly, quantitative longitudinal studies involving Finnish children at elementary school and their mothers (Silinskas et al., 2015; Sikiö et al., 2017) assessed maternal help in homework, maternal levels of warmth and behavioral control in parenting styles, as well as children's reading comprehension and pseudoword spelling abilities. According to the results, the most beneficial style of involvement with homework entailed positive parental affect and interaction.

Consistently, as stated in the OECD (2012) report on the parent factor in education, based on questionnaires distributed in thirteen countries, parents who read to their young children, and who engage in conversation with their adolescent children around the dinner table are more likely to have a significant impact on their children language-skills outcomes in secondary school. Positive parent-child interactions such as these, marked by genuine enjoyment, interest and engagement, have a long-lasting effect when they begin at a young age and continue throughout the child's development, beyond homework supervision. An authoritative parenting style, with high levels of warmth, autonomy-support and appropriate expectations, is regarded nowadays (Goodall, 2013) as the most promotive of effective parental engagement in all areas of children's development, and supportive of their growth and learning as whole persons.

Whole-person development or educating the whole child are well-known terms within holistic educational paradigms. Such paradigms are adopted by schools that value the children's learning context, that consider all areas of development just as important as academic achievement, and that pay attention to each child's feelings, aspirations and ideas (Miller, 2000). However, if such a paradigm is to be fruitful, schools and parents must collaborate closely, as a 'whole child' does not learn only in school or while doing homework. Although teachers around the world implement a whole-person approach in their classrooms (FNBE - Finnish National Board of Education, 2016; DGE Direção-Geral de Ensino, 2017), most schools fail to encourage parents to engage with learning from a holistic perspective, and parental involvement practices at home might end up not serving children's and families' best interests (Goodall, 2017). The recent shift in research, from school-centered to learningcentered parental involvement practices, highlight the need to enhance knowledge about different ways parents may support their children's learning at home.

\section{Parental Mindset in the Home Learning Environment}

Parental engagement is a major asset promoting children's learning, but each family's reality is unique. Thus, engagement experiences at home may vary, influenced by parental motivation and role beliefs, teachers' requests or children's attributes (Deslandes and Rousseau, 2007; Eccles, 2007; Pomerantz et al., 2012). Parents have implicit beliefs about the abilities of their children (Dweck and Leggett, 1988; Dweck, 2000; Moorman and Pomerantz, 2010). In other words, they either engage in learningrelated situations in the belief that their children's abilities are malleable and that their learning can be developed (a growth mindset or incremental implicit theory), or they believe that their children's abilities are static and that there are some things they may never learn (a fixed mindset or entity implicit theory) (Rautiainen et al., 2016).

Within the framework of implicit theories (Dweck and Leggett, 1988; Dweck, 2000) is a substantial number of studies on the impact of a growth or a fixed mindset on people themselves and on those around them (Blackwell et al., 2007; Zhang et al., 2017). An individual with a growth mindset concerning intelligence, for example, believes that people can become more 
and more intelligent through experience, whereas someone with a fixed mindset believes that people are either permanently intelligent or not. Such implicit beliefs form a complex network of tendentially incremental or entity meaning systems, which tend to be activated in challenging situations (Plaks et al., 2009). In this study, we use mindset as a standard term that also encapsulates implicit beliefs and implicit meaning systems.

Mindsets are somewhat generalizable, in other words extendable to a variety of contexts (Dweck, 2000), but they may as well vary in different domains (Dweck et al., 1995). For example, someone might have a growth mindset about general intelligence, but a domain-specific fixed mindset in how they approach challenging math tasks (Gunderson et al., 2017).

Mindset theory has been studied in classroom and school contexts (e.g., Ronkainen et al., 2019; Seaton, 2018), underlining the role of the adult in building children's self-esteem. One of the most relevant discoveries from research on implicit theories is that praising children for their ability (person praise), instead of for their effort or strategies (process praise), undermines their motivation (Mueller and Dweck, 1998; Glerum et al., 2020 ), in that they devote energy not only to achieving a goal (mastery-oriented), but also to making sure they look smart in the eyes of others (performance-oriented). A framework for growth mindset pedagogy in basic education was recently developed and applied in Finland in a qualitative study (Rissanen et al., 2019). The authors concluded that certain features of the teaching style created a growth mindset atmosphere and were likely to boost student learning. These features included, among other things, avoiding judging students too quickly, promoting mastery-oriented rather than comparison-oriented learning, providing honest feedback in the form of "not yet," not shielding students from challenging situations, praising strategies and effort, emphasizing the positive aspects of challenges, failure, and mistakes in learning, and fostering situational attribution, i.e., behavior instead of traits.

Although home and school environments differ in nature and purpose, both constitute the two major childhood scenarios in which the young rely heavily on encouragement from adults to keep on joyfully embracing learning opportunities. It could thus be argued that a growth mindset atmosphere created in the classroom may find home learning equivalents in various features of parent-child learning-related dynamics (see Stern and Hertel, 2020, in this edition). However, most research on the parental mindset concerns its associations with the mindset of their children and their achievements (e.g., Rautiainen et al., 2016; Rowe and Leech, 2019), and sheds little light on the processes in which growth mindset parents engage to support their children's learning at home. Strengthening this trend, recent studies identify parental encouragement of effort as the most important feature of parent-child communication aimed at fostering a growth mindset in the child, more strongly predictive than the parents' own growth mindset (Haimovitz and Dweck, 2016, 2017). According to the authors, parental beliefs about the motivating or demotivating effects of failure, and their responses to their children's failure, are associated with various parental practices. Such incremental or entity implicit beliefs originate, respectively, in a failure-is-enhancing mindset meaning that the parent encourages process-focused thinking in their children to overcome challenges, or in a failure-is-debilitating mindset that may prevent their children from pushing further.

Schiffrin et al. (2019) recently carried out a quantitative study on this approach to failure. They adopted the term helicopter parenting to describe an overly involved and controlling parenting style that provides a level of developmentally inappropriate problem-solving assistance. Among the sample of 275 18- to- 25-year-olds, those reporting a failure-is-debilitating (as opposed to a failure-is-enhancing) parental mindset were also more likely to report helicopter parenting behaviors in their fathers.

In another study, Muenks et al. (2015) combined parental beliefs about their children's ability and practices of engagement at home. Their aim was to explore the beliefs of 300 parents about the fixedness of their children's abilities, based on questionnaire responses and self-reported mastery-oriented and autonomy-supportive behaviors. According to their findings, the more strongly the parents believed their children's abilities were fixed, the more readily they endorsed controlling (as opposed to autonomy-supportive) and performance-oriented (as opposed to mastery-oriented) behaviors at home, and the less frequently they reported engaging in academically related activities with their children in the home environment. Beyond the sphere of academically related engagement, Justice and collaborators (Justice et al., 2020) recently conducted a comparative quantitative study involving 497 United States and Danish parents of children aged from 3 to 5 years. They specifically set out to explore the association (if any) of a parental mindset related to ability and effort with home learning activities at home. Among the four practices of parental engagement they studied (family learning activities, learning extensions, parental time investment, and parental school involvement), the results showed that parents' effort mindset was a predictor of family learning activities at home and of parental time investment, and that the country moderated the relationship between an effort mindset and parental time investment. In the study, an effort mindset referred to the extent to which parents' beliefs reflected the importance of effort in their children's learning.

It is suggested that a complex network of implicit parental beliefs about their children's abilities is connected to a growth or fixed mindset (Plaks et al., 2009; Haimovitz and Dweck, 2016, 2017), that is constantly actualized in their relationships. Not only do mindsets affect praise and failure feedback, but they also tend to take over in any learning-related situation, especially challenging ones. In the case of a growth mindset, incremental implicit beliefs will actualize in the encouragement of persistence and process-focused thinking, implying that learning is a work in progress, and that it is a good thing (Rissanen et al., 2019). On the other hand, in the case of a fixed mindset, entity implicit beliefs will actualize in a crystalized way of interpreting people and situations, and the need to persist will be seen as a permanent weakness (Moorman and Pomerantz, 2010). It often happens that beliefs actualize in a combined and less antagonistic mixed form, thus mindsets should be perceived as one spectrum instead of two fixed opposite concepts. Given that implicit beliefs develop as a way of organizing one's world and giving meaning to 
experiences (Dweck, 2000, 2017), they may fluctuate depending on the motivation and the emotion. In one specific domain and at one given time, an individual may tend toward either a fixed or a growth mindset (Seaton, 2018), but may as well show both growth and fixed tendencies in their behavior, indicating a mixed mindset (e.g., Laine et al., 2016).

Following a long period of positive attention and dissemination, the applicability of the mindset theory has been largely questioned in the last decade, especially due to failed mindset interventions replication and applicability (Dweck and Yeager, 2019; Yeager et al., 2019). After looking carefully into past research and conducting new studies, the mindset theory is building stronger assets to its foundation and confirming its applicability to learning contexts by two means: (a) recognizing and highlighting the central role of the environment revolving any mindset intervention, e.g., school culture, classroom climate and age of target-group (Dweck and Yeager, 2019), and (b) attempting to bring together complex psychological phenomena (Dweck, 2017) and an array of disciplines of study (Dweck and Yeager, 2019) to model effective mindset interventions. Such enlargement of scope, that considers people's beliefs, emotions, motivation, personality and intertwined environment, provides a rich framework to study parental engagement practices and mindsets in the home environment.

\section{The Aim of the Study}

The present study is part of the University of Helsinki's Copernicus project, which explores the implicit beliefs of parents, teachers and students, as well as home-school collaboration, in different cultural contexts. This study focuses on the parental role in children's learning, in Finland and Portugal. Our aim is, in an analysis of parental narratives, to characterize engagement with their children's learning at home, and the implicit beliefs about learning that underlie such engagement. The research questions are as follows.

(1) How do parents engage with their children's learning at home?

(2) How do parents' implicit beliefs about learning actualize in such engagement?

(3) What kind of engagement-mindset profiles are identifiable amongst the parents?

\section{MATERIALS AND METHODS}

\section{Participants and Procedure}

In seeking answers to our questions, we adopted a qualitative approach based on in-depth interviews. We sent invitation e-mails to a set of 50 Finnish English-speaking parents who had previously collaborated with the Copernicus project by answering a mindset survey in 2016 or 2017. The Portuguese parents received an invitation from the principal of the respective schools, and those wishing to collaborate enrolled through a hyperlink. All parents who volunteered were interviewed. The participants $(N=19)$ were parents of first- to sixth-grade children, ten Finnish parents from Helsinki and nine Portuguese parents from Lisbon.
In Finland, the parents came from two schools located in different socio-economic urban neighborhoods in Helsinki, to ensure diversity of parental experiences and narratives. One school with 900 students provides basic education from grades one to nine, and the other has 940 students in basic to upper-secondary education. The Portuguese parents came from one five-school agrupamento educating 2,550 pupils from kindergarten to the secondary level. Schools in Portugal work in groups (agrupamentos) of neighboring schools with complementary levels, under the same administration. Following the same principle as in Finland, we selected a Portuguese agrupamento that was in a heterogeneous and urban neighborhood.

The interviews in Finland were conducted in February 2020 and took place in different locations including the schools, the neighborhood library and the participants' homes. The Portuguese parents were interviewed between March and June 2020, via the videocall software Zoom on account of the coronavirus pandemic. The researcher took all the necessary precautions to ensure the participants' privacy and safety during face-to-face and online interviews. The Finnish and the Portuguese participants were interviewed in English and Portuguese, respectively.

Participation in the study was voluntary. The participants were informed that the interview concerned their engagement with their children's learning, and they signed an informed consent form regarding their participation (Finnish Advisory Board on Research Integrity, 2009). A more detailed explanation of the mindset-related purpose of the study was given after each interview, to ensure that it would not influence the parents' responses.

Table 1 gives background information about the parents, including mean age, gender, education, and child's grade. Parents' mean age were 43 years old $\left(\mathrm{M}_{\mathrm{all}}=43.84 ; \mathrm{SD}_{\mathrm{all}}=8.21\right)$. In Finland, the mean age of parents was $47\left(\mathrm{M}_{\text {Finn }}=47\right.$; $\mathrm{SD}_{\text {Finn }}=9.01 ; \operatorname{Min}_{\text {Finn }}=40 ; \operatorname{Max}_{\text {Finn }}=70$ ), whereas, in Portugal, it was 40 years old $\left(\mathrm{M}_{\text {Port }}=40.33\right.$; $\mathrm{SD}_{\text {Port }}=5.83$; Min $_{\text {Port }}=29$; Maxport $=50)$. Most participants were female $\left(\mathrm{n}_{F}=14 ; \mathrm{n}_{M}=5\right)$, and only one Portuguese mother, among all parents, did not have a university degree.

TABLE 1 | Participants' background information.

\begin{tabular}{lcc}
\hline & Finland $\mathbf{N}=\mathbf{1 0}$ & Portugal $\mathbf{N}=\mathbf{9}$ \\
\hline $\begin{array}{l}\text { Age (in years) mean (SD) } \\
\text { Gender }\end{array}$ & $47(9)$ & $40.33(5.8)$ \\
Female & 6 & 7 \\
Male & 4 & 2 \\
Education & & \\
Secondary education & 0 & 1 \\
Higher education & 10 & 8 \\
Child's grade & & \\
1st and 2nd & 0 & 5 \\
3rd and 4th & 3 & 2 \\
5th and 6th & 7 & 2
\end{tabular}




\section{Instruments}

We used a semi-structured interview protocol to ensure consistency, while also allowing for spontaneous narratives to emerge (Legard et al., 2003). This study's data comes from a broader study about parental engagement practices and mindset. Interviewees were asked to speak rather freely about the topics of parental engagement with their children's learning at home and at school, dealing with their children's challenges and successes in learning, and parent-teacher learning-related collaboration. The opening question was Please, tell me about what in your opinion makes for a successful teacherparent partnership? The narratives were followed by clarifying questions by the researcher, who would lead the conversation to the subsequent topic of discussion in a natural manner. Indicative questions used in the present study are What does parental engagement with learning mean, from your point of view? How can parents engage with learning at home? or Can you recall a challenging learning episode that took place at home and how you approached it? Can you recall a successful learning episode that took place at home and how you approached it? The sequence of questions varied from one interview to the other, to favor the spontaneous flow of the conversations.

The protocol was based on the literature (e.g., Goodall, 2013; Haimovitz and Dweck, 2017) and aimed at eliciting descriptions not only of the parents' experiences, but also their context, e.g., learning-related implicit beliefs, attitudes, and processes underlying engagement in the child's learning. The interviews varied in length from 30 to $120 \mathrm{~min}$, the average length being $1 \mathrm{~h}$. They were audio-recorded and later transcribed, generating 213 pages of text.

Before the interview, the parents filled in a short demographic questionnaire. They were also informed that the term 'at home' referred to all non-school-related occasions, such as in the park. Additionally, parents were asked what the word 'learning' meant in their own understanding. All definitions shared by the participants conveyed an idea of learning as an ongoing phenomenon in their children's lives and independent from the school context. It was thereby guaranteed a common interviewer-interviewee conceptualization of learning.

\section{Analysis}

A content-analysis method was employed to study the data. We chose content analysis because it is commonly used in research aimed at enhancing understanding of and retrieving meaning from rich verbal data in an objective and systematic manner (Krippendorf, 2004; Schreier, 2012). The unit of analysis varied from parts of sentences to whole paragraphs. As a criterion, each coded excerpt should constitute an independent element of meaning about the phenomena (Elo and Kyngäs, 2008). Atlas.ti 8 software was used to facilitate the analysis.

To find answers to our first research question we carried out an inductive content analysis, given that our purpose was to identify and contextualize forms of parental engagement in the home. Thus, all the codes derived from the data (Elo and Kyngäs, 2008). First, the first author coded each interview regarding parental engagement at home. Every time a new engagementrelated topic emerged a new code was created. Second, through a process of reflection and discussion, the first and the second authors clustered the codes into thirteen subcategories, then five broader subcategories and, finally, in two main categories. The process necessitated iterative analyses of the data. Example 1 demonstrates a unit of analysis related to engagement in the schooling process, of which the code was studying the clock, subcategory supporting studying, broader subcategory helping with schooling-related activities, and main category engagement with the children's schooling process.

Example 1: She started to learn to tell the time at school, and it was a little bit difficult for me [to help her], because it is a little bit abstract. I tried to get something concrete. So, we drew a clock, you know, we had scissors and everything. We had a little bit of fun and did our own clock and then we started to practice with that. (Parent 16)

With regard to the second research question, we used the features of a growth mindset, or incremental implicit beliefs, as the units of analysis that would convey intelligence as malleable, and challenges as boosters of learning. The features of a fixed mindset, or entity implicit beliefs, on the other hand, were the units that connoted intelligence as stable, and challenges as obstacles in the learning process. Within each main mindset category, we created six mirroring subcategories based on the theoretical model, e.g., giving process-focused (growth) and person-focused (fixed) praise. One fixed mindset subcategory was later merged with a similar one, giving a total of eleven subcategories. Example 2 exemplifies a unit of analysis related to a growth mindset of which the code was embracing challenges, subcategory encouraging the seeking of challenging learning situations and main category growth mindset.

Example 2: The learning journey has been spectacular. Because it has been hard, but, as I tell him, the hard things are the interesting ones [...] it has been very good, because we all learn every day, from the good and the less good moments. (Parent 3)

We read through the transcripts of the interviews multiple times to make sure that we would interpret contexts and meanings as accurately as possible. To achieve consensus, the first and the second author reflected upon the coding decisions on four different occasions. Disagreements were discussed and recoded jointly.

In the final phase of the analysis, to answer our third research question and identify parental engagement-mindset profiles, we considered each interview as a whole. We calculated the frequencies of statements for the main categories separately for each parent so that we would be able to detect which aspects of parental engagement and mindset were emphasized in individual parental narratives (Tuomi and Sarajärvi, 2002). The statements were calculated per parent to determine whether he or she had described his/her engagement mostly related to the schooling process, or had engaged with his/her child mostly in an integrated way, i.e., engaging in holistic development. An overall engagement tendency was defined as holistic when the parent had more than $50 \%$ of engagement statements in 
the main category engagement with their children's holistic development. Similarly, parents with over $50 \%$ of statements in the main category engagement with their children's schooling process were classified as having schooling-focused engagement in their children's learning. Even though engaging with the schooling process is considered an integral part of engaging with the holistic development (Goodall and Montgomery, 2014), the distinction here presented is possible, because the authors recognize engagement with the holistic development as the third and major point of the engagement continuum, that globalizes all forms of engaging with learning. Because all parents narrated engaging with their children's schooling process and holistic development, it is necessary to point out that parental engagement-mindset profiles reflect patterns found in our data, collected and analyzed in specific occasions. Therefore, they portray a tendency of engagement, instead of the whole continuum a parent and child might navigate through, in their learning-related interactions.

With regard to the parental mindset, those whose statements concentrated between $75 \%$ and $100 \%$ in the growth mindset category were assumed to have an overall Growth Mindset (GM). All the remaining parents' mindsets were classified as Mixed Mindset (MM) because their statements aligned with both the growth mindset and fixed mindset categories. Four parental profiles were created on the basis of the calculations.

\section{RESULTS}

\section{Parental Engagement With Their Children's Learning at Home}

The first research question concerned how Finnish and Portuguese parents engaged in their children's learning at home: a total of 313 statements $\left(f_{\text {Finn }}=171 ; f_{\text {Port }}=142\right)$ citing parental engagement were identified and coded (see Table 2 ).

As Table 2 shows, parental engagement practices were classified in two main categories based on whether narratives reflected engagement with children's schooling process or holistic development. No major differences between the Finnish and the Portuguese parents were identified in this respect, therefore we assess the results as a single group. The narrative exemplars transcribed below have been selected based on how well they represent the data in each category.

The first main category, engagement with the children's holistic development $(f=191)$, was prominent, the emphasis being on cultivating the relationship $(f=86)$ with their children and developing the character $(f=68)$. The following statements well demonstrate how parents in our sample see showing interest in their children as an intrinsic part of being engaged.

[Parental engagement] is my own interest and motivation to follow how my child is learning, what he is learning, how he is doing, what are the challenges for him. [...] And I feel it is very normal that I make some observations and I follow how he is doing. [...] The child should feel and experience that the parent is always ready to give support, to give his knowledge, to back this [learning] process. (Parent 18, Finnish, Female, 44 years old)
To me, [engaging] is the interest we as parents have in the children's education ... it is asking how their day went, to know about them, how did the school day go, what went well, what did not, if they remember what they learned, chats they have had during the day with classmates. (Parent 3, Portuguese, Male, 40 years old)

Similarly, encouraging autonomy $(f=37)$ was the highlight of developing the character in learning-related experiences at home, as one parent said about his fifth grader.

\begin{abstract}
What is needed is to [...] develop in the child the autonomy to be organized. Because, if not, then the child will be by herself until eleven in the evening [...] So, what we do is 'okay, you have until seven o'clock to do your homework.' When it's seven, then, it's over. 'Couldn't complete it? Well, next time you have to manage your time better.' That's what we try to stimulate in her, organizing skills. (Parent 9, Portuguese, Male, 41 years old)
\end{abstract}

There were also references to supporting leisure-time activities $(f=37)$. Here, parents spoke of engagement as providing opportunities to try new skills and experiences $(f=23)$ beyond the world of school, as shown by the following mother.

\footnotetext{
We gave our daughter a book about programming for kids and bought, actually, this kind of small computer for kids, so she could start learning coding. Something that is in between, that are not books from school, but also not random. (Parent 13, Finnish, Female, 40 years old)
}

The second main category, engagement with the children's schooling process $(f=122)$, was strongly present in the parental experiences of engagement at home. The emphasis was on directly helping with schooling-related activities $(f=77)$. Within this main category, supervising homework $(f=44)$ and supporting studying $(f=25)$ were recurrent topics of engagement. This Portuguese mother exemplifies her approach to homework supervision.

Being engaged is [...] to know what the children are learning, what they are doing, not necessarily knowing the content matter or being beside them doing the homework together, but at least, supervising, paying attention, being always, always present. (Parent 6, Portuguese, Female, 44 years old)

Parents also reported indirectly engaging in their children's learning at home while updating their schooling-related information $(f=45)$ : examples include knowing their children's school routine $(f=20)$, communicating with the teacher $(f=20)$ and seeking information about the curriculum $(f=4)$. The parents highlighted the importance of knowing what happens in the school and reaching out to the teacher if necessary, for instance.

\section{Parents' Implicit Beliefs and Their Actualization in Parental Engagement at Home}

The responses to the second research question concerning the actualization of the parents' implicit beliefs at home are presented as a table of frequencies (Table 3) showing which features of a growth and a fixed mindset prevailed in the 
TABLE 2 | Frequencies of the subcategories and main categories of parental engagement at home.

\begin{tabular}{|c|c|c|c|}
\hline \multirow[t]{2}{*}{ Parents engaged with... } & \multicolumn{3}{|c|}{ Number of statements } \\
\hline & Finnish $(N=10) f(\%)$ & Portuguese $(N=9) f(\%)$ & Total $(N=19) f(\%)$ \\
\hline Their children's holistic development & $96(56)$ & $95(67)$ & $191(61)$ \\
\hline Cultivating the relationship & $38(22)$ & $48(34)$ & $86(27)$ \\
\hline Showing interest in their children & $34(20)$ & $43(30)$ & $77(24)$ \\
\hline Taking the role of a parent & $4(2)$ & $5(4)$ & $9(3)$ \\
\hline Developing the character & $39(23)$ & $29(20)$ & $68(22)$ \\
\hline Encouraging autonomy & $24(14)$ & $13(9)$ & $37(12)$ \\
\hline Teaching morality and rules & $8(5)$ & $9(6)$ & $17(6)$ \\
\hline Giving socio-emotional support & $7(4)$ & $7(5)$ & $14(4)$ \\
\hline Supporting leisure-time activities & $19(11)$ & $18(13)$ & 37 (12) \\
\hline Providing new skills and experiences & $14(8)$ & $9(6,5)$ & $23(7)$ \\
\hline Spending leisure time together & $5(3)$ & $9(6,5)$ & $14(5)$ \\
\hline Their children's schooling process & $75(44)$ & $47(33)$ & $122(39)$ \\
\hline Helping with schooling-related activities & $48(28)$ & $29(20)$ & $77(25)$ \\
\hline Supervising homework & $28(16)$ & $16(11)$ & $44(14)$ \\
\hline Supporting studying & $14(8)$ & $11(8)$ & $25(8)$ \\
\hline Preparing for exams & $6(4)$ & $2(1)$ & $8(3)$ \\
\hline Updating schooling-related information & $27(16)$ & $18(13)$ & $45(14)$ \\
\hline Knowing their children's school routine & $15(9)$ & $5(4)$ & $20(6)$ \\
\hline Communicating with the teacher & $9(5)$ & $12(8)$ & $21(7)$ \\
\hline Seeking information about the curriculum & $3(2)$ & $1(1)$ & $4(1)$ \\
\hline Total of statements & 171 & 142 & 313 \\
\hline
\end{tabular}

TABLE 3 | Actualization of parents' implicit beliefs about learning in their parental engagement at home.

\begin{tabular}{|c|c|c|c|}
\hline \multirow[t]{2}{*}{ Parental implicit beliefs actualized in a... } & \multicolumn{3}{|c|}{ Number of statements } \\
\hline & Finnish $(N=10) f(\%)$ & Portuguese $(N=9) f(\%)$ & Total $(N=19) f(\%)$ \\
\hline Growth mindset & $126(77)$ & $108(89)$ & $234(82)$ \\
\hline Considering the child's learning context and emotions & $25(15)$ & $46(38)$ & $71(25)$ \\
\hline Encouraging effort, persistence and practice & $36(22)$ & $19(16)$ & $55(19)$ \\
\hline Approaching difficulties as a natural part of learning and suggesting strategies & $23(13)$ & $12(10)$ & $33(12)$ \\
\hline Encouraging the seeking of challenging learning situations & $21(14)$ & $9(7)$ & $32(11)$ \\
\hline Giving process-focused praise & $16(10)$ & $11(9)$ & $27(10)$ \\
\hline Advising to ask questions when in doubt & $5(3)$ & $11(9)$ & $16(5)$ \\
\hline Fixed mindset & $38(23)$ & $14(11)$ & $52(18)$ \\
\hline Interpreting personality & $16(10)$ & $10(8)$ & $26(9)$ \\
\hline Comparing and rewarding performance & $12(7)$ & $1(0,5)$ & $13(4)$ \\
\hline Approaching difficulties as obstacles to learning & $3(1,5)$ & $2(2)$ & $5(2)$ \\
\hline Admiring effortless success & $4(3)$ & $1(0,5)$ & $5(2)$ \\
\hline Giving person-focused praise & $3(1,5)$ & $0(0)$ & $3(1)$ \\
\hline Total of statements & 164 & 122 & 286 \\
\hline
\end{tabular}

interviewees' narratives. We identified a total of 286 relevant statements $\left(f_{\text {Finn }}=164 ; f_{\text {Port }}=122\right)$ indicative of parents' implicit beliefs about learning.

Next, we consider the most prominent subcategories in more detail. In general, we discuss the results as a whole, given that there were no major differences between the Finnish and the Portuguese parents. At some points in this section we discuss interpretations of the growth and fixed categories together given that they mirror each other, even though they are reported in separate segments in Table 3.
As Table 3 shows, the parents' engagement narratives were consistently embedded in a growth mindset $(f=234)$, which was demonstrated in how they considered the child's learning context and emotions $(f=71)$ in the situation, rather than fixed traits such as interpreting personality $(f=26)$.

Other indications of a growth mindset were evident in their discourse, such as encouraging effort, persistence and practice ( $f=55)$, as opposed to admiring effortless success $(f=5)$, which is indicative of a fixed mindset. Features indicating a growth mindset tended to relate to process-focused praising $(f=27)$, 
whereas fixed mindset-related person-focused praising $(f=3)$ was seldom used. The following statement about giving feedback to her first grader about her success in a difficult writing task reflects both subcategories: encouraging effort, persistence and practice and process-focused praising.

I always congratulate her, because all victories are victories. You can only win the war with various smaller battles. I say 'You see? You just needed to have patience. Of course, if you work, you are calm and patient, things will get done.' (Parent 7, Portuguese, Female, 35 years old)

Further evidence of growth mindset thinking in the parents' narratives relates to approaching difficulties as a natural part of learning and suggesting strategies $(f=33)$ for overcoming them, whereas responses reflecting the fixed mindset subcategory approaching difficulties as obstacles to learning $(f=5)$ were fewer. Avoiding the comfort zone and encouraging children to seek challenging learning situations $(f=32)$ was another prominent feature evidencing a growth mindset in the parents' discourse, especially among the Finnish respondents $\left(f_{\text {Finn }}=21 ; f_{\text {Port }}=9\right)$. The following statement falls into this subcategory. The parent talks about allowing his children to explore the city without adult supervision.

The kids are expanding their area all the time, and we are trying to let them do that [...] We let them explore the world and hopefully not just sit and use their phones all day. And this is also an educational thing, that they take responsibility for themselves, [that] they know what to do if they get lost or if they hurt themselves or if they get hungry, [that] they know how to use money, to interact with people they don't know. (Parent 14, Finnish, Male, 43 years old)

Finally, although the fixed mindset subcategories were not prevalent, comparing and rewarding performance $(f=13)$ featured in the Finnish parents' narratives $\left(f_{\text {Finn }}=12 ; f_{\text {Port }}=1\right)$ : $7 \%$ of the relevant statements mention some kind of material rewarding of children's achievements - such as a present, money or candy - based on an expected standard of performance. We should nevertheless point out that few statements were assigned to this subcategory.

Although the frequency tables were a major support in terms of identifying patterns in our data, we were intent on accessing individuals and understanding how their implicit meaning system connected to their overall engagement in their children's learning at home. In the next step of the analysis, we attempted to realize these associations and to situate parents, accordingly.

\section{Parental Engagement-Mindset Profiles}

To answer our third research question about what engagementmindset profiles could be identified among the parents, we analyzed each participant's overall tendency to engage with learning and their mindsets about learning. We calculated the frequencies of statements for the main categories for each parent and built four parental profiles based on the calculations. Table 4 and Figure 1 illustrate the process and present the results.

Figure 1 depicts learning-related parental engagement and mindsets combined in four profiles, thereby giving a clearer picture of how parental mindsets actualize in their engagement with their children at home. The underlined text below refers to the names of the profiles; text in italics refers to the subcategories of engagement, reported in Table 2; and text in bold refers to the mindset subcategories, reported in Table 3.

Most of the parents we studied exhibited a growth mindset to support the child's holistic development $(n=12, \mathrm{nFinn}=5$, nPort $=7$ ). They treated their children as whole persons and engaged in their home learning in multiple ways, taking special advantage of spontaneous day-to-day routine as opportunities for engagement. The following statement exemplifies the actualization of a growth mindset in approaching difficulties as a natural part of learning and suggesting strategies for overcoming them when teaching about morality and rules and encouraging autonomy.

I told him how bad fake news is. [Because he appeared in a newspaper article], I told him 'tell me whenever you get the first message from anyone that you don't know, that seems to be somehow suspicious, a wrong message, show it to me. We can check it together if it's some kind of scam, because his name is out there now. I told him 'it is possible that your face and some naked body will be put together, and that they ask you for money. It is possible if somebody wants to be mean' [...] He takes so many things into account, and I don't try to stop him by giving him unrelated, irrational orders. I rely on sensible talk and discussion. (Parent 17, Finnish, Male, 70 years old)

The growth mindset of parents with this profile was also actualized in encouraging effort, persistence and practice and considering the child's learning context and emotions when supporting studying. A Finnish father and a Portuguese mother illustrate this in the examples below, when talking about their children's homework challenges.

I think that what we've tried to tell them is that if you work you will learn. That if you. . It's not about being stupid, it's about doing more work. Because they might be frustrated and [say] that 'I'm stupid, I don't get it, I hate it,' and stop working and stop thinking. So we try to embrace their self-confidence [and say] 'it's not you, it's just that you need more time, and you need to focus on it.' (Parent 14, Finnish, Male, 43 years old)

I help her with the homework... if I notice she is too tired and starting to act out and refusing it, I stop for a while and say look, we'll finish this later today,' because they do get tired, you know. (Parent 2, Portuguese, Female, 41 years old)

Parents with the profile mixed mindset to support the child's holistic development $[n=2$, nFinn $=1$ (Parent 10), nPort $=1$ (Parent 4)], also varied in their engagement at home. However, the variation was more evenly distributed between schoolingrelated and holistic engagement, meaning that these parents tended to engage more in the schooling process, compared to the previous group. The following example is a narrative of socio-emotional support from parent 4 . She describes praising her daughter when she passed the level test for her swimming class, after receiving many negative behavior-related comments from the instructor in the previous months. She uses growth mindset process-focused praise, interspersed with a fixed mindset interpretation of her child's characteristics as fixed traits, i.e., interpreting personality. 


\begin{tabular}{|c|c|c|c|c|c|c|c|c|c|c|c|c|c|c|}
\hline \multirow{3}{*}{ Parent } & \multirow{3}{*}{$\begin{array}{l}\text { Country } \\
\text { Portugal }\end{array}$} & \multicolumn{5}{|c|}{ Parental engagement $f(\%)$} & \multirow{3}{*}{$\begin{array}{c}\text { Result } \\
\mathrm{H}\end{array}$} & \multicolumn{5}{|c|}{ Mindset $f(\%)$} & \multirow[b]{2}{*}{ Result } & \multirow[b]{2}{*}{ Profiles } \\
\hline & & \multirow{2}{*}{$\begin{array}{c}\text { Statements }(\boldsymbol{f}) \\
16\end{array}$} & \multicolumn{2}{|c|}{ Schooling (S) } & \multicolumn{2}{|c|}{ Holistic (H) } & & \multirow{2}{*}{$\begin{array}{c}\text { Statements }(\boldsymbol{f}) \\
7\end{array}$} & \multicolumn{2}{|c|}{ Fixed (FM) } & \multicolumn{2}{|c|}{ Growth (GM) } & & \\
\hline & & & 3 & (19) & 13 & (81) & & & 0 & (0) & 7 & (100) & GM & Holistic development and growth mindset \\
\hline 3 & Portugal & 18 & 2 & (12) & 16 & (88) & $\mathrm{H}$ & 13 & 0 & (0) & 13 & (100) & GM & \\
\hline 5 & Portugal & 5 & 1 & (20) & 4 & $(80)$ & $\mathrm{H}$ & 15 & 1 & $(7)$ & 14 & (93) & GM & \\
\hline 7 & Portugal & 24 & 11 & (46) & 13 & $(54)$ & $\mathrm{H}$ & 24 & 3 & (13) & 21 & $(87)$ & GM & \\
\hline 8 & Portugal & 17 & 3 & (18) & 14 & (82) & $\mathrm{H}$ & 13 & 0 & (0) & 13 & (100) & GM & \\
\hline 9 & Portugal & 7 & 0 & (0) & 7 & $(100)$ & $\mathrm{H}$ & 7 & 0 & (0) & 7 & (100) & GM & \\
\hline 12 & Finland & 11 & 4 & (36) & 7 & $(64)$ & $\mathrm{H}$ & 8 & 0 & (0) & 8 & (100) & GM & \\
\hline 13 & Finland & 21 & 10 & (47) & 11 & (53) & $\mathrm{H}$ & 15 & 0 & (0) & 15 & (100) & GM & \\
\hline 14 & Finland & 22 & 5 & (23) & 17 & $(77)$ & $\mathrm{H}$ & 15 & 0 & (0) & 15 & (100) & GM & \\
\hline 17 & Finland & 11 & 2 & (18) & 9 & (82) & $\mathrm{H}$ & 18 & 4 & (22) & 14 & (78) & GM & \\
\hline 18 & Finland & 30 & 11 & (37) & 19 & (63) & $\mathrm{H}$ & 25 & 2 & (8) & 23 & (92) & GM & \\
\hline 11 & Finland & 7 & 4 & (57) & 3 & (43) & $S$ & 11 & 4 & (36) & 7 & (64) & MM & Schooling process and mixed mindset \\
\hline 15 & Finland & 7 & 4 & (57) & 3 & (43) & $\mathrm{s}$ & 13 & 4 & (31) & 9 & (69) & MM & \\
\hline 19 & Finland & 16 & 11 & (69) & 5 & $(31)$ & S & 18 & 14 & (78) & 4 & $(22)$ & MM & \\
\hline 1 & Portugal & 9 & 7 & (78) & 2 & (22) & $\mathrm{s}$ & 9 & 2 & (22) & 7 & (78) & GM & Schooling process and growth mindset \\
\hline 16 & Finland & 22 & 12 & (55) & 10 & $(45)$ & $S$ & 27 & 2 & $(7)$ & 25 & (93) & GM & \\
\hline 4 & Portugal & 16 & 7 & (44) & 9 & $(56)$ & $\mathrm{H}$ & 17 & 8 & $(47)$ & 9 & $(53)$ & MM & Holistic development and mixed mindset \\
\hline 10 & Finland & 5 & 2 & (40) & 3 & $(60)$ & $\mathrm{H}$ & 14 & 8 & $(57)$ & 6 & $(43)$ & MM & \\
\hline
\end{tabular}




\begin{tabular}{|c|c|c|}
\hline & $\begin{array}{l}\text { Parental engagement with } \\
\text { the schooling process }\end{array}$ & $\begin{array}{l}\text { Parental engagement with } \\
\text { the holistic development }\end{array}$ \\
\hline $\begin{array}{l}\text { Growth } \\
\text { mindset }\end{array}$ & $\begin{array}{l}\text { Growth mindset } \\
\text { to support the schooling } \\
\text { process } \\
\text { Finn: } 1 \text { Port: } 1\end{array}$ & $\begin{array}{l}\text { Growth mindset } \\
\text { to support the holistic } \\
\text { development } \\
\text { Finn: } 5 \text { Port: } 7\end{array}$ \\
\hline $\begin{array}{l}\text { Mixed } \\
\text { mindset }\end{array}$ & $\begin{array}{c}\text { Mixed mindset } \\
\text { to support the schooling } \\
\text { process } \\
\text { Finn: } 3 \text { Port: } 0\end{array}$ & $\begin{array}{l}\text { Mixed mindset } \\
\text { to support the holistic } \\
\text { development } \\
\text { Finn: } 1 \text { Port: } 1\end{array}$ \\
\hline
\end{tabular}

FIGURE 1 | Parental engagement-mindset profiles.

My attitude is always positive and in the sense of sharing her enthusiasm, 'wow, how awesome, you did it! You see [what happens] when you put in effort,' I try to show her the path she has walked along. If she had difficulties in the beginning, I try to make her see what she managed to overcome, 'do you remember how you did it before? You put in effort, now you achieved your goal, the path is not always easy, but if we put in effort, we can achieve our goals.' [...] And she gets happy, but she is normally a lazy person, really lazy, and only once in a while does she show this spectacular side.

(Parent 4, Portuguese, Female, 40 years old)

Two parents were placed in the growth mindset to support the child's schooling process $(n=2$, nFinn $=1$, nPort $=1$ ) profile, and three parents in the mixed mindset to support the child's schooling process profile $(n=3, \mathrm{nFinn}=3, \mathrm{nPort}=0)$. Both profiles represent the parental approach of engaging in learning concentrated on schoolingrelated activities, but the mindset differs. Thus, although parents in the former group may be more supportive of their children's mistakes and their individual learning contexts as students, those in the latter group may convey standard-related expectations and a negative message with regard to learning difficulties.

The following statement, from a parent with a growth mindset to support the child's schooling process profile, shows how her growth mindset actualizes in her process-focused praise and encouragement of effort, persistence and practice when she gives feedback to her child related to achieving good marks in school exams, i.e., preparing for exams.

I encourage her 'this is the way to go,' but I never tell her that she has to be the best, because she doesn't. We have to be the best of ourselves, give it our best, not to be better than others [...] school is not a race. (Parent 1, Portuguese, Female, 29 years old)

In the final example, on the other hand, which is from a parent in the mixed mindset to support the child's schooling process profile, the mixed learning-related mindset actualizes in supporting studying at home. Having considered this respondent's (Parent 19) position in Table 4, we understood the dominance of schooling-process-related engagement. In terms of mindset, the frequencies point to a prevalence of a fixed mindset $(f=14$, $78 \%$ ). In the example, when the mother talks about her child's mathematics skills she fits in the fixed mindset subcategory comparing and rewarding performance in using standardized comparisons, but she also reveals a growth mindset at the end of her discourse, specifically within the subcategories considering the child's learning context and emotions specific of the pre-puberty stage of development and approaching difficulties as a natural part of learning that will be eventually 'figured out.'

Her multiplication skills were a bit weaker, so during the summer I made cards and I told her that we needed to do the multiplication tables. I saw the way she was doing her math, that she was slow [...] I thought 'at this age, she should have known it really fast by now and not have to think so long' [...] And now she is getting lazy again about doing her multiplication tables, so it didn't stay with her. So, I thought 'yeah, I'm going to have to do it again.' This year it is probably going to be harder, because she is eleven and she thinks she is a teenager, so it's a big fight with the 'I don't want to do it.' She's in the pre-puberty stage, so it's a lot of 'no, no,' and sure that's an obstacle, but that is also quite normal and we're still trying to figure that out. (Parent 19, Finnish, Female, 45 years old)

\section{DISCUSSION}

Our aim in this study was to make a qualitative contribution to the growing interest on parental engagement and growth mindset. Assessed by means of both inductive and deductive content analysis, our data comprised parental narratives about how they engaged in their children's learning at home, and how their mindset actualized in such engagement. We were also interested in finding out which parental profiles, if any, the combined framework of parental engagement as a continuum and the implicit theories (Dweck, 2000; Goodall and Montgomery, 2014) would generate. The study's participants were parents of 7- to 12-year-old children from two countries, Finland and Portugal. A further aim was to identify countryspecific patterns of engagement and mindset actualization.

It is important to underline that conclusions derived from our study refer to a specific set of participants and their personal experiences, which does not allow generalizations, but apply only to the participants who have been interviewed. Moreover, the data gathered and analyzed captures a small sample of parents' experiences of engagement, narrated by themselves and interpreted and reported by the researchers of this study. This means that parental profiles are far from static and exact. Nevertheless, their interviews constitute a rich first-person set of narratives of interactions with their children, that allowed a detailed study of parental engagement and mindset in the home environment. This is one of the most relevant advantages of conducting qualitative research (Elo and Kyngäs, 2008).

\section{Parental Engagement Practices at Home}

Because our findings revealed no major differences between how Finnish and Portuguese parents engaged with their children at home, we opted to analyze the results of the whole group of nineteen parents. From the perspective of parental engagement as a continuum that encompasses parent-child learning-related interactions of different complexity of involvement, we found out that the interviewed parents engaged in learning at home 
in a balanced manner, navigating through both their children's schooling process and their children's holistic development. While maintaining their role of reference in supporting their children's academic activities, such as supervising homework and supporting studying, the majority of the parents were aware of the extent to which simple everyday parenting activities such as showing an active interest in their children, encouraging autonomy, teaching them about morality and rules, and giving them opportunities to extend their skills and experiences beyond the school context, constituted key learning-related parental engagement initiatives that supported an integrated development of their child. Parents talked about their children's learning in a broad sense, from the beginning, tending to see learning as a natural part of experiencing life, in and outside the school.

Our results highlight the importance of approaching parental engagement in the home learning environment as a continuum ranging from schooling-related activities to the most spontaneous and genuine parent-child interactions in natural, school-independent settings (Goodall and Montgomery, 2014). In other words, focusing on the holistic development of the child. Although not generalizable, the fact that our strongest subcategory was cultivating the relationship adds a building block to the research regarding the importance of supportive and warm parenting styles in learning-related activities at home (OECD, 2012; Goodall, 2013; Silinskas et al., 2015; Sikiö et al., 2017). The results also point to the necessity of shifting the central role of homework involvement as the major context of parent learning-related engagement at home (Hill and Tyson, 2009) among parents of school age children. Scholars (e.g., Goodall, 2017) have called attention to the lack of attention of schools that already adopt holistic educational paradigms in the classroom in instructing families to engage in their children's holistic development at home. In that respect, our findings allow us to infer that our parents were well informed and awaken the importance of supporting their children's feelings, aspirations and ideas in different areas of development, not only in the academic realm (Miller, 2000). Although parents' level of formal education might be a plausible explanation, this still raises the question of whether the participants benefited from effective home-school partnership and teacher-parent communication that gave them the incentive to engage in such actions at home (Goodall, 2017).

\section{Actualization of Mindset in Engagement}

With regard to learning-related mindsets among parents, our results contribute to the growing interest on the association between mindset and parental engagement. We found evidence that a growth mindset featured in the vast majority of our participants' experiences of engagement with their children's learning. This implies that the interviewed parents, when engaging with their children's learning, conveyed the hidden message that their learning could be developed by means of effort and practice. Fixed mindset hidden messages, such as that children's learning outcomes depended on their fixed personality traits, were also present in our data, although much less frequently. These findings are in line with the results of previous research postulating that parents develop patterned implicit beliefs about their children's abilities (Dweck, 2000; Moorman and Pomerantz, 2010; Rautiainen et al., 2016). More specifically related to mindset and parental involvement practices, our findings are in line with previous research (Muenks et al., 2015; Schiffrin et al., 2019) that showed that parents who engaged in academic activities at home evidenced a growth mindset regarding their children's learning-related failure and ability.

Moreover, there is evidence that effort mindset is a predictor of parental engagement in family learning activities as well as time investment at home (Justice et al., 2020). Not only do our findings complement such evidence, but they also bring it to another level of analysis in allowing us to form a clear picture of such associations. Our main contribution comprises the parental engagement-mindset profiles we were able to draw up.

\section{Parental Engagement-Mindset Profiles}

Growth mindset features were distributed amongst all the parental profiles, differing only in terms of frequency. Both growth mindset and mixed mindset profiles were identified in the interviewed parents' narratives of engagement. Among the parents with a growth mindset, the overall tendency was to engage with the child's holistic development, instead of solely engaging with the child's schooling process. Parents in the mixed mindset group shared examples of engagement that implied a need to be, to some extent, constantly informed about their children's lives, and their narratives relied less on examples of engagement in autonomy-supportive interactions. These findings are in line with the results of previous research reporting associations between a helicopter parenting style and a failureis-debilitating mindset (Schiffrin et al., 2019). When compared to the growth mindset group of parents, the mixed mindset parents interviewed by us more frequently focused their engagement narratives solely in schooling-related activities at home. This finding adds controversy to the debate on engagementmindset research (Muenks et al., 2015) that concludes that less autonomy-supportive parents show a tendency to engage less in academically related activities at home. Given that Muenks et al. (2015) explored no other kinds of engagement beyond the academic sphere, and that they assessed mindset by means of questionnaires, we cannot agree or disagree with the findings. What we are able to conclude from our research is that parents in both the growth and the mixed mindset profile groups engaged in different ways with their children's learning, varying in emphasis between supporting their child's schooling process alone or supporting their child's holistic development, where the schooling process is as important as all other learning-related experiences of the child.

The majority of the parents in our study were situated in the growth mindset profiles, within which the most common was growth mindset to support the child's holistic development. These findings build on the recent work of Justice et al. (2020): they found that a parental mindset supporting their children's efforts to develop their abilities was a predictor of family learning activities such as telling stories, playing sports and doing science projects, and of parental investment in time at home. Our results reveal an association of a parental growth mindset, including acknowledgment of the role of effort in 
learning, with broader forms of engagement that include shared leisure and other enjoyable activities. Parents in the growth mindset to support the child's holistic development profile gave examples of engagement involving calmer, more relaxed and spontaneous learning contexts. One possible interpretation is that these parents might not feel such a strong need to closely follow their children's learning process, which would allow them more time to engage in spontaneous and/or school-independent activities. This is in line with previous research on parenting styles and homework assistance implying that close schoolingrelated parental support could be a reaction to learning difficulties experienced by children, the researchers having found out that such engagement is associated with low schooling outcomes (Silinskas et al., 2015).

Finally, our results reveal how complex and dynamic the implicit meaning systems of parents can be in terms of their actualization in support of learning. We found that mindsets may actualize in different ways along the mindset spectrum (Dweck, 2000), depending on the context. All our parents used a variety of strategies to support their children's learning at home and to meet their learning needs, thereby evidencing a dynamic and ever-developing relationship with their children. We stress the importance of studying the parental mindset in relation to their engagement in learning at home in context, given that mindset is likely to manifest as mixed, even in one specific type of interaction such as parent-child communication. One good example of this is the way various parents with a growth mindset in our sample referred to offering and giving material rewards to their children and sometimes compared their outcomes to a standard. If not analyzed in context and in light of parental engagement as a broad concept, such as only with a questionnaire, such parental profiles may be open to misinterpretation, and end up being regarded as fixed mindset.

It is necessary to take into account while interpreting our results the fact that, with the exception of one parent whose highest level of education was secondary school, all parents had university degrees. This brings important implications to this discussion of findings, as it is likely to influence parents' practices of parental engagement at many levels. Well-educated parents may benefit from more resources, such as money or time flexibility, and an easier access to information and guidance, such as academic research on parenting or reliable professionals.

\section{Implications}

The present research contributes to the debate on parental engagement and a growth mindset from a unique perspective, by combining implicit theories and parental engagement theoretical conceptualizations, studying children and families beyond the preschool context, and content analyzing parents' own narratives. We did not set out with an initial hypothesis, nor were we intent on confirming or refuting evidence presented in previous studies. On the contrary, we aimed to open the door on the engagementmindset debate even wider. Our study gives insights into the association between growth mindset and engagement practices, and suggests optimal contexts for supporting children's learning. It also highlights the need for qualitative research on the parental mindset in the home learning environment.
In terms of practice, this research should attract the attention of school principals and teachers. Each child's home environment must be taken into account in any attempt to foster whole-child learning. These clear examples of growth and fixed mindset actualization in parental engagement illustrate how schools should approach parents, specifically in terms of what to encourage and how to advise them on homerelated engagement. For instance, when a child shows signs of learning difficulties in school-related matters, it is not uncommon that parents receive instructions to reinforce the children's schooling at home. Many times, this prolonging of school hours in the home may have a negative impact in parentchild relationships (Silinskas et al., 2015; Sikiö et al., 2017). Our findings support the argument that teachers should instruct parents to engage with their children's learning at home from a holistic point of view, investing their time together in both school- and non-school related activities. Additionally, teachers could enhance parents' awareness about the fact that their communication with their children is constantly embedded in incremental or entity implicit theories, and about how to build a growth mindset environment at home when supporting children's learning. Such apparently simple and light support from schools may have the power to disseminate a growth mindset atmosphere at home (Dweck, 2010), and thereby to break down barriers to the engagement of all families (Goodall, 2017).

\section{Limitations}

We interviewed nineteen parents for this research, therefore the results cannot be generalized. Moreover, the small numbers of participants from each country do not allow for reliable cross-cultural comparisons. We therefore recommend that future research on the topic should encompass a larger number of participants, as well as different cultural backgrounds.

Another limitation concerns the background profile of the participants. Even though the selected schools were heterogeneous to ensure variability in parental experiences and realities, all the participants who reached out to us and wanted to collaborate had a university degree, with the exception of one mother who had completed secondary education. Even though we did not measure the socio-economic status of the parents, it was evident that none of them faced fundamental challenges, such as financial, to be engaged with their children's learning, and all were aware of the need to do so. Parental engagement is an important tool that schools could use to fight against inequality and to close the achievement gap between low- and high-income families (Goodall, 2017). We therefore recommend that in future qualitative research every effort should be made to listen to and give space to a more diverse group of participants.

We should also address the methodological limitations of our study. The results we present here are not crystalized portraits of participants' engagement practices and implicit beliefs. No methodology could provide such portraits, but we suggest that future research should use combined qualitative data-collection methods such as interviews and non-participant observations 
to support the researcher's interpretations of parental narratives and actions. The outbreak of the coronavirus pandemic in the beginning of our data collection phase posed major challenges and adaptations to our initial plan. Therefore, we recommend future researchers to draw contingency plans from start when planning qualitative research based on face-to-face interviews.

Despite the limitations and constraints, this paper has considerable strengths. Besides the methodological design already mentioned, the fact that the first author also conducted and transcribed all the interviews is one of them, as it allowed a thorough and detailed study of the meanings in the participants' narratives.

\section{DATA AVAILABILITY STATEMENT}

The raw data supporting the conclusions of this article will be made available by the authors, upon request.

\section{REFERENCES}

Blackwell, L. S., Trzesniewski, K. H., and Dweck, C. S. (2007). Implicit theories of intelligence predict achievement across an adolescent transition: a longitudinal study and an intervention. Child Dev. 78, 246-263. doi: 10.1111/j.1467-8624. 2007.00995.x

Braunschweig, P. S., Kappler, C., and Chiapparini, E. (2019). No more homework? negotiations of parental engagement in all-day schools. Int. J. About Parents Educ. 11, 46-54. doi: 10.5281/zenodo.3570753

Chen, J., Pisani, L., White, S., and Soroui, J. (2012). Parental engagement in early childhood education at home. Read. Psychol. 33, 497-524. doi: 10.1080/ 02702711.2012 .703038

Cooper, H., Lindsay, J. J., and Nye, B. (2000). Homework in the home: how student, family, and parenting-style differences relate to the homework process. Contemp. Educ. Psychol. 25, 464-487. doi: 10.1006/ceps.1999.1036

Deslandes, R., and Rousseau, N. (2007). Congruence between teachers' and parents' role construction and expectations about their involvement in homework. Int. J. About Parents Educ. 1, 108-116.

DGE - Direção-Geral de Ensino (2017). Perfil Dos Alunos à Saída da Escolaridade Obrigatória. Available online at: https://dge.mec.pt/sites/default/ files/Curriculo/Projeto_Autonomia_e_Flexibilidade/perfil_dos_alunos.pdf (accessed on October 20, 2020).

Dweck, C. S. (2000). Self-Theories: Their Role in Motivation, Personality and Development. New York, NY: Psychology Press.

Dweck, C. S. (2006). Mindset: The new psychology of success. Random House.

Dweck, C. S. (2010). Mind-sets and equitable education. Principal Leadersh. 10, 26-29.

Dweck, C. S. (2017). From needs to goals and representations: foundations for a unified theory of motivation, personality, and development. Psychol. Rev. 124, 689-719. doi: 10.1037/rev0000082

Dweck, C. S., Chiu, C.-Y., and Hong, Y.-Y. (1995). Implicit theories and their role in judgments and reactions: a word from two perspectives. Psychol. Inq. 6, 267-285. doi: 10.1207/s15327965pli0604_1

Dweck, C. S., and Leggett, E. L. (1988). A social-cognitive approach to motivation and personality. Psychol. Rev. 95, 256-273. doi: 10.1037/0033-295X.95.2.256

Dweck, C. S., and Yeager, D. S. (2019). Mindsets: a view from two eras. Perspect. Psychol. Sci. 14, 481-496. doi: 10.1177/1745691618804166

Eccles, J. (2007). "Families, schools and developing achievement motivations and engagement," in Handbook of Socialization: Theory and Research, eds J. Grusec and P. Hastings (New York, NY: The Guilford Press), 665-691.

Elo, S., and Kyngäs, H. (2008). The qualitative content analysis process. J. Adv. Nurs. 62, 107-115.

\section{ETHICS STATEMENT}

This study followed the ethical guidelines of the Finnish Advisory Board on Research Integrity. The participants provided their written informed consent to participate in this study.

\section{AUTHOR CONTRIBUTIONS}

$\mathrm{CL}, \mathrm{EK}$, and KT developed the research project. CL administered the data collection and analyses, with the contribution of EK and KT. All authors contributed to the article and approved the submitted version.

\section{FUNDING}

This work was supported by a grant received from the Finnish National Agency for Education (EDUFI: TM-19-11247).

Epstein, J. (2011). School, Family and Community Partnerships - Preparing Educators and Improving Schools. Boulder, CO: Westview Press.

Finnish Advisory Board on Research Integrity (2009). Ethical Principles of Research in the Humanities and Social and Behavioural Sciences and Proposals for Ethical Review. Available Online at: https://www.tenk.fi/en/ethical-review-in-humansciences (accessed on October 20, 2020).

FNBE - Finnish National Board of Education (2016). National Core Curriculum for Basic Education 2014. Helsinki: Finnish National Board of Education Publications.

Glerum, J., Loyens, S., Wijnia, L., and Rikers, R. (2020). The effects of praise for effort versus praise for intelligence on vocational education students. Educ. Psychol. 40, 1270-1286. doi: 10.1080/01443410.2019.1625306

Goodall, J. (2013). Parental engagement to support children's learning: a six point model. Sch. Leadersh. Manag. 33, 133-150. doi: 10.1080/13632434.2012.72 4668

Goodall, J. (2017). Learning-centred parental engagement: freire reimagined. Educ. Rev. 70, 603-621. doi: 10.1080/00131911.2017.1358697

Goodall, J., and Montgomery, C. (2014). Parental involvement to parental engagement: a continuum. Educ. Rev. 66, 399-410. doi: 10.1080/00131911.2013. 781576

Grolnick, W. S., Benjet, C., Kurowski, C. O., and Apostoleris, N. H. (1997). Predictors of parent involvement in children's schooling. J. Educ. Psychol. 89, 538-548. doi: 10.1037/0022-0663.89.3.538

Grolnick, W. S., and Slowiaczek, M. L. (1994). Parents' involvement in children's schooling: a multidimensional conceptualization and motivational model. Child Dev. 65, 237-252. doi: 10.2307/1131378

Gunderson, E. A., Hamdan, N., Sorhagen, N. S., and D'Esterre, A. P. (2017). Who needs innate ability to succeed in math and literacy? Academic-domain-specific theories of intelligence about peers versus adults. Dev. Psychol. 53, 1188-1205. doi: $10.1037 /$ dev0000282

Haimovitz, K., and Dweck, C. (2017). What predicts children's fixed and growth intelligence mind-sets? Not their parents' views of intelligence but their parents' views of failure. Psychol. Sci. 27, 859-869. doi: 10.1177/0956797616639727

Haimovitz, K., and Dweck, C. S. (2016). What predicts children's fixed and growth intelligence mind-sets? Not their parents' views of intelligence but their parents' views of failure. Psychol. Sci. 27, 859-869.

Hill, N., and Tyson, D. (2009). Parental involvement in middle school: a metaanalytic assessment of the strategies that promote achievement. Dev. Psychol. 45, 740-763. doi: 10.1037/a0015362

Jeynes, W. H. (2007). The relationship between parental involvement and urban secondary school student academic achievement. Urban Educ. 42, 82-110. doi: $10.1177 / 0042085906293818$ 
Justice, L., Purtell, K., Bleses, D., and Cho, S. (2020). Parents' growth mindset and home learning activities: a cross-cultural comparison of Danish and U.S. parents. Front. Psychol. 11:1365. doi: 10.3389/fpsyg.2020.01365

Krippendorf, K. (2004). Reliability in content analysis: some common misconceptions and recommendations. Hum. Commun. Res. 30, 411-433. doi: 10.1111/j.1468-2958.2004.tb00738.x

Laine, S., Kuusisto, E., and Tirri, K. (2016). Finnish teachers' conceptions of giftedness. J. Educ. Gifted 39, 151-167. doi: 10.1177/0162353216640936

Larsson, S. (1998). On Quality in Qualitative Studies. Education on-line. Published version in Swedish: Larsson, S. (1993/2005). Om kvalitet i kvalitativa studier. Nordisk Pedagogic, 25(1), 16-35. Available online at: www.leeds. ac.uk/educol/documents/000000821.htm (accessed on September, 5).

Legard, R., Keegan, J., and Ward, K. (2003). "In-depth Interviews," in Qualitative Research Practice, eds J. Richie and J. Lewis (London: Sage), 139-168.

Levinthal, C., and Kuusisto, E. (2020). "Parental engagement in children's learning: a holistic approach to teacher-parents' partnerships," in Pedagogy in Basic and Higher Education: Current Developments and Challenges, eds K. Tirri and A. Toom (London: IntechOpen), 203-219. doi: 10.5772/intechopen.89841

Mata, L., Pedro, I., and Peixoto, F. (2018). Parental support, student motivational orientation and achievement: the impact of emotions. Int. J. Emot. Educ. 10, 77-92.

Miller, R. (2000). Caring for a New Life: Essays on Holistic Education. Vermont: Foundation for Educational Renewal.

Moorman, E. A., and Pomerantz, E. M. (2010). Ability mindsets influence the quality of mothers' involvement in children's learning: an experimental investigation. Dev. Psychol. 46, 1354-1362. doi: 10.1037/a0020376

Mueller, C. M., and Dweck, C. S. (1998). Praise for intelligence can undermine children's motivation and performance. J. Personal. Soc. Psychol. 75, 33-52. doi: 10.1037/0022-3514.75.1.33

Muenks, K., Miele, D., Ramani, G., Stapleton, L., and Rowe, M. (2015). Parental beliefs about the fixedness of ability. J. Appl. Dev. Psychol. 41, 78-89. doi: 10.1016/j.appdev.2015.08.002

OECD (2012). Let's Read Them a Story! The Parent Factor in Education. Paris: PISA, OECD Publishing, doi: 10.1787/9789264176232-en

OECD (2018). The Future of Education and Skills - Education 2030. Available online at: https://www.oecd.org/education/2030/E2030\%20Position\%20Paper \%20(05.04.2018).pdf (accessed on October 20, 2020).

Plaks, J. E., Levy, S. R., and Dweck, C. S. (2009). Lay theories of personality: cornerstones of meaning in social cognition. Soc. Personal. Psychol. Compass 3, 1069-1081. doi: 10.1111/j.1751-9004.2009.00222.x

Pomerantz, E. M., Kim, E. M., and Cheung, C. S. (2012). "Parents' involvement in children's learning," in APA Educational Psychology Handbook: Individual differences and Cultural and Contextual Factors, Vol. 2, eds K. R. Harris, S. Graham, and T. Urdan (Washington, DC: American Psychological Association), 417-440. doi: 10.1037/13274.017

Rautiainen, R., Räty, H., and Kasanen, K. (2016). Is children's intelligence malleable? Parental perspectives on implicit theories of intelligence. Nordic Psychol. 68, 233-243. doi: 10.1080/19012276.2016.1149093

Rissanen, I., Kuusisto, E., Tuominen, M., and Tirri, K. (2019). In search of a growth mindset pedagogy: a case study of one teacher's classroom practices in a Finnish elementary school. Teach. Teacher Educ. 77, 204-213. doi: 10.1016/j.tate.2018. 10.002
Ronkainen, R., Kuusisto, E., and Tirri, K. (2019). Growth mindset in teaching: a case study of a Finnish elementary school teacher. Int. J. Learn. Teach. Educ. Res. 18, 141-154. doi: 10.26803/ijlter.18.8.9

Rowe, M. L., and Leech, K. A. (2019). A parent intervention with a growth mindset approach improves children's early gesture and vocabulary development. Dev. Sci. 22:e12792. doi: 10.1111/desc.12792

Schiffrin, H. H., Yost, J. C., Power, V., Saldanha, E. R., and Sendrick, E. (2019). Examining the relationship between helicopter parenting and emerging adults' mindsets using the consolidated helicopter parenting scale. J. Child Fam. Stud. 28, 1207-1219. doi: 10.1007/s10826-019-01360-5

Schreier, M. (2012). Qualitative Content Analysis in Practice. London: Sage.

Seaton, F. S. (2018). Empowering teachers to implement a growth mindset. Educ. Psychol. Pract. 34, 41-57. doi: 10.1080/02667363.2017.1382333

Sikiö, R., Siekkinen, M., Holopainen, L., Silinskas, G., Lerkkanen, M., and Nurmi, J. (2017). Maternal parenting styles, homework help, and children's literacy development in language minority and Finnish-speaking families. Eur. J. Psychol. Educ. 33, 235-250. doi: 10.1007/s10212-017-0330-4

Silinskas, G., Kiuru, N., Aunola, K., Lerkkanen, M. K., and Nurmi, J. E. (2015). The developmental dynamics of children's academic performance and mothers' homework-related affect and practices. Dev. Psychol. 51, 419-433. doi: 10.1037/ a0038908

Stern, M., and Hertel, S. (2020). Profiles of parents' beliefs about their child's intelligence and self-regulation: a latent profile analysis. Front. Psychol. 11:610262. doi: 10.3389/fpsyg.2020.610262 Advance only publication,

Sylva, K., Melhuish, E., Blatchford, I., and Taggart, B. (2004). The Effective Provision of Preschool Education (EPPE) Project: Technical Paper 12 - the Final Report: Effective Pre-School Education. London: DfES/Institute of Education, University of London.

Tirri, K. (2014). The last 40 years in Finnish teacher education. J. Educ. Teach. 40, 600-609. doi: 10.1080/02607476.2014.956545

Tuomi, J., and Sarajärvi, A. (2002). Laadullinen Tutkimus ja Sisällöanalyysi [Qualitative research and content analysis]. Helsinki: Tammi.

Wilder, S. (2014). Effects of parental involvement on academic achievement: a meta-synthesis. Educ. Rev. 66, 377-397. doi: 10.1080/00131911.2013.780009

Yeager, D. S., Hanselman, P., Walton, G. M., Murray, J. S., Crosnoe, R., Muller, C., et al. (2019). A national experiment reveals where a growth mindset improves achievement. Nature 573, 364-369.

Zhang, J., Kuusisto, E., and Tirri, K. (2017). How teachers' and students' mindsets in learning have been studied: research findings on mindset and academic achievement. Psychology 8, 1363-1377. doi: 10.4236/psych.2017.8 9089

Conflict of Interest: The authors declare that the research was conducted in the absence of any commercial or financial relationships that could be construed as a potential conflict of interest.

Copyright (c) 2021 Levinthal, Kuusisto and Tirri. This is an open-access article distributed under the terms of the Creative Commons Attribution License (CC BY). The use, distribution or reproduction in other forums is permitted, provided the original author(s) and the copyright owner(s) are credited and that the original publication in this journal is cited, in accordance with accepted academic practice. No use, distribution or reproduction is permitted which does not comply with these terms. 